\title{
SOBRE EL ORIGEN DEL QUINTO PASO DEL DELEYTOSO DE LOPE DE RUEDA
}

\author{
Arno Gimber. \\ Universidad Jules Verne. Amiens.
}

\begin{abstract}
El paso de Lope de Rueda que figura como número cinco en el Deleytoso, editado por Timoneda en 1567 , es quizá aparte del famoso paso séptimo, llamado por Moratín Las aceitunas, el más conocido del autor sevillano. Cayetano Alberto de la Barrera lo tituló La tierra de Jauja y la crítica se ha preguntado varias veces sobre el origen concreto de esta pieza, cuestión muy compleja por la ausencia del motivo de tierra de Jauja en la literatura de la Edad Media española por un lado y por la gran difusión del mismo motivo en las demás literaturas europeas desde la antigüedad ${ }^{1}$.

La pieza de Rueda tiene un argumento escaso como es inherente a todas las obras del género del teatro menor. Dos ladrones, Honzigera y Panarizo, que se descubren tanto por sus nombres como por la utilización del lenguaje de germanía como miembros de la capa criminal de la sociedad, dialogan en una primera parte de tan sólo 11 parlamentos sobre su situación de escasos medios y de hambre. Honzigera tiene el plan de quitar a un simple llamado Mendrugo (nomen est omen) "una caçuela de ciertas viandas" que éste lleva a su mujer, presa en la cárcel. Ambos ladrones ponen en práctica su proyecto en la segunda parte del paso, de 68 breves parlamentos, aplicando como artimaña burlesca la narración de la historia de la tierra de Jauja. Al oírla, Mendrugo se maravilla, y en un momento de descuido los pícaros se van con la cazuela. Cierra el paso el simple preguntándose por qué le habrán quitado la comida quienes conocen una tierra tan abundante como la que le acaban de describir.
\end{abstract}

1 Dieter Richter, Schlaraffenland: Geschichte einer populären Phantasie, Köln, Dietrichs, 1984.

3 Lucian of Samosata, Vera Historia, en A. M. Harmon, ed., Works of Lucian of Samosata, vol. 1, The Loeb Classical Library, London/Cambridge, William Heinemann/ Harvad University Press, 1972, págs. 247-357. 
El cuentecillo del país de Jauja, eje central del paso, retoma algunos tópicos de la descripción de esta utopía, digamos popular, como la recompensa del que duerme y el castigo del que trabaja, o como varios elementos sobre la comida (los ríos de miel y de leche, edificios construidos con materias comestibles), ya que la pereza y la gula son los placeres principales de este paraíso terrestre. Sin embargo, faltan otros lugares comunes como la libertad sexual o la fecundidad acelerada de la naturaleza, que desde las primeras apariciones del motivo en la literatura clásica ${ }^{2}$ pertenecen a las características del género.

Asensio ${ }^{3}$ parte en su monografía sobre el entremés, de un origen folklórico del motivo de Jauja y supone la existencia de una conseja medieval en la literatura española hoy perdida y similar al primer texto en una lengua vernácula, el dit francés Le pays de Cocagne ${ }^{4}$ del siglo xıII. José Luis Canet Vallés asume en su reciente edición de los pasos del autor sevillano esta suposición ${ }^{5}$, con lo cual se incorpora a la nueva tendencia de la crítica de buscar las fuentes de la creación literaria de Lope de Rueda en la literatura española medieval y renacentista ${ }^{6}$. La influencia italiana sobre la obra de Lope de Rueda, punto de vista que domina en los trabajos críticos sobre este autor a partir del artículo de Stiefel ${ }^{7}$, pierde entonces cierto valor y debe ser revisada.

Aunque este nuevo enfoque de la crítica sea legítimo, no puede ser válido para todos los casos, pues no conocemos ningún texto de tierra de Jauja en la literatura española medieval. El término "Jauja" remite a la época de la conquista de América, ya que se trata del nombre de un pueblo de Córdoba que designa también un valle y una provincia en el Perú que por su fertilidad y buen clima se difunde en la literatura que habla de los paraísos mundanos ${ }^{8}$. La palabra "cucaña" sin embargo aparece en el Libro de buen amor

3 Eugenio Asensio, Itinerario del entremés. Desde Lope de Rueda a Quiñones de Benavente, Madrid, Gredos, 2. ${ }^{\mathrm{a}}$ ed., 1971, pág. 47.

4 V. Väänänen, ed., "Le 'fabliau' de Cocagne. Le motif du pays d'abondance dans le folklore occidental", Neuphilologische Mitteilungen, 48, 1947, págs. 3-36.

- Lope de Rueda, Pasos, ed. José Luis Canet Vallés, Madrid, Castalia, 1992, página 146 , nota 103 .

- Manuel V. Diago Moncholi, "Lope de Rueda y los orígenes del teatro profesional", Criticón, 50, 1990, págs. 41-65; un primer intento se percibe ya en Joan Oleza Simó, "Hipótesis sobre la génesis de la comedia barroca y la historia teatral del xvi", en J. Oleza Simó, ed., Teatros y prácticas escénicas $I$ : El Quinientos valenciano, València, Instituto Alfonso el Magnànim, 1984, págs. 9-41, aquí págs. 30 y sigs.

7 A. L. Stiefel, "Lope de Rueda und das italienische Lustspiel", Zeitschrift für romanische Philologie, 15, 1891, págs. 338-343; Othón Arróniz, La influencia italiana en al nacimiento de la comedia española, Madrid, Gredos, 1969, págs. 73-134.

8 Julio Caro Baroja, Jardin de flores raras. Quiromancia, mitologia, alquimia, paises imaginarios, Barcelona, Seix Barral, 1993, págs. 51-63. Sobre la etimología de las palabras 'jauja' y 'cucaña' véase también J. Corominas, Diccionario crítico etimológico de 
como sinónimo de engaño ${ }^{9}$ y según el Diccionario de Autoridades su origen etimológico se encuentra en la lengua italiana, circunstancia que refleja a nuestro parecer la filiación literaria del motivo de la tierra de Jauja.

Vemos un cierto parecido con la literatura cucañera en el episodio de la Dama del Lago Encantado, intercalado en la narración del Caballero Zifar, texto temprano y atípico del género caballeresco. Es un ejemplo que se aparta de nuestro motivo si lo comparamos con los textos franceses, ingleses, flamencos, alemanes y también italianos en la Edad Media, donde aparecen descripciones de comida y bebida en abundancia o de excesos sexuales sin castigo ${ }^{10}$.

En el capítulo llamado "De las maravillas quel cauallero Atreuido vido dentro en el lago, de lo qual el fue mucho maravillado" se nos presenta un mundo paradisíaco que más bien se corresponde con las descripciones de las islas de los bienaventurados en la literatura clásica, o las de la Jerusalén celeste en el Apocalipsis 21, por la mención de la arquitectura con materiales preciosos. No hay que descartar, por otra parte, una posible influencia de la literatura árabe en el mencionado episodio. Sólo el elemento de una fertilidad extraordinaria - "todos los arboles desta tierra e las yeruas nasçen e floresçen e dan fruto nuevo de cada dia, e las otras reses paren a syete dias" "- y la breve mención de comida en abundancia respaldan la tesis de que en este caso se trata de una descripción de un mundo utópico parecido a una tierra de Jauja. Sin embargo, la omisión de varios rasgos característicos del motivo de Cucaña y la inserción de un tono moralista por parte del autor, demuestran que este texto no pertenece a la misma tradición de países de Jauja en la literatura medieval. La historia intercalada en el $\mathrm{Ca}$ ballero Zifar se presenta como un exemplo. Al final, las maravillas en el reino de la Dama Blanca son juzgadas por el autor como diabólicas y la moraleja se dirige contra los hombres que, movidos por la curiosidad, entran en espacios que no les corresponden.

la lengua castellana, Madrid, Gredos, 1954, donde se considera menos probable el origen de 'jauja' en un regionalismo catalán, 'xauxar-se', con el significado de 'burlarse'.

- Arcipreste de Hita, Libro de buen amor, ed. B. G. Gybbon-Monypenny, Madrid, Castalia, 1988, pág. 135, versos 122a-b: "Del escolar goloso, compafiero de cucaña, / fize esta otra troba [...]", y pág. 176, verso 341 b.

10 De la crítica abundante sobre el tema son representativos Dieter Richter, op. cit., y W. Wunderlich, "Das Schlaraffenland in der deutschen Sprache und Literatur: Bibliographie und Forschungsstand", Fabula. Zeitschrift für Ersählforschung, 27, 1986, págs. 54-75. Para la cultura italiana citaremos el libro de G. Cocchiara, Il paese di Cuccagna e altri studi di folklore, Torino, 1956, y para Espafia el artículo de F. Delpech, "Aspects des pays de Cocagne. Programme pour une recherche", en Jean Lafond/ Augustin Redondo, eds., L'image dic monde renversé et ses représentations littéraires et paralittéraires de la fin du $X V I^{*}$ siècle au miliew du $X V I I^{*}$. Colloque international, Tour, 17-19 Novembre 1977, Paris, Librairie philosophique J. Virin, 1979, págs. 35-48.

11 Libro del Caballero Zifar, ed. Cristina González, Madrid, Cátedra, 1983, pág. 244. 
En la literatura italiana es donde más aparece el motivo de Jauja tanto en la Edad Media como en el Renacimiento ${ }^{12}$. El primer testigo se encuentra en el Decamerón, en el tercer cuento de la octava jornada. En él, al igual que en la obrilla de Lope de Rueda, se combina la descripción de una tierra de Jauja alimentaria y ociosa con una burla que urde Maso del Saggio a Calandrino, pintor "semplice e di nuovi costumi" ${ }^{13}$. Es de suponer que Lope de Rueda conocía la obra de Boccaccio, pero el argumento, el engaño con las piedras, es bien diferente y las descripciones del país de Jauja no tienen coincidencias en las dos obras. Sólo el hecho de que el motivo de la tierra de Jauja esté combinado con una burla inclinan a Randolf W. Listerman ${ }^{14}$ a establecer relaciones entre ambos autores.

Existen, sin embargo, otros textos italianos que unen igualmente elementos descriptivos y elementos burlescos. Pier Luigi Crovetto ${ }^{15}$ encuentra similitudes entre el paso de Rueda y una pieza de la commedia dell'arte, en un episodio de la primera jornada de la Burle d'Isabella, donde dos bribones vacían la cesta de un simple mientras le cuentan la historia de la tierra de Jauja. Sin embargo, estudios recientes ${ }^{16}$ han demostrado que la influencia de la commedia dell'arte en la obra de Lope de Rueda difícilmente puede haberse ejercido en su propia época por la transmisión exclusivamente oral de estas obras hasta casi finales del siglo xvi y por la actuación no mucho antes de las compañías teatrales italianas en España.

De finales del siglo $\mathrm{xv}$ poseemos una obra, la Storia de Campriano Contadino, que trata de las burlas que gasta el protagonista, un campesino astuto, a tres mercaderes. Una de las picardías, el episodio del asno que caga monedas de oro, es conocida en todas las literaturas europeas. Su larga tradición folklórica se remonta a una poesía en latín, Unibos, del siglo $\mathrm{x}$ u xII, probablemente compuesta en un monasterio francés. De las versiones en lengua italiana se conocen ejemplares impresos a partir de finales del siglo xv. En el último episodio los mercaderes quieren acabar con Campriano, le meten en un saco, lo cierran y encargan a un pastor que lo eche al agua. El malévolo Campriano convence con engaños al pastor para que ocupe su puesto, le echa al agua a él y de paso se queda con su rebaño de ovejas. Llegan los mercaderes, y ante su extrañeza por encontrarlo vivo, él

\footnotetext{
12 J. Delumeau, La mort des Pays de Cocagne. Comportements collectifs de la Renaissancce d lâge classique, Paris, Publications de la Sorbonne, 1976.

13 G. Boccaccio, Decameron, a cura di Vittore Branca, vol. 1, Milano, Arnoldo Mondadori, 1985, pág. 647.

14 R. W. Listermann, "Lope de Rueda's 'La Tierra de Jauja'", The USF Language Quarterly, 14, 1975, págs. 16 y 22.

15 Pier Luigi Crovetto, "Convenzionalità e originalità nel 'Deleitoso' di Lope de Rueda, Cultura Neolatina, 34, 1974, págs. 73-97.

16 Manuel V. Diago Moncholi, art. cit.
} 
les cuenta que sí fue echado al agua, pero que en el fondo vio un país de maravillas del que al final salió incluso con dinero suficiente para comprar las ovejas ${ }^{17}$.

Lo que importa en nuestro contexto es que la descripción del país de maravillas debajo del agua coincide con las descripciones de las islas o tierras de Cucaña en las tradiciones italianas, francesas e inglesas.

Del mismo cuentecillo folklórico existe una versión española, Cómo un rústico labrador engañó a unos mercaderes, conservado en un pliego suelto del British Museum ${ }^{18}$, en la que falta por completo la historia de la tierra de Jauja. Lo que el campesino pretende haber visto en el fondo del agua, lo reduce a una sola frase como en el poema latino: "Empero alli donde me echásteis hallé infinito tesoro, de lo cual tomé lo que quise y he comprado este ganado." Esta eliminación demuestra claramente la no-difusión, incluso la falta de una tradición cucañera en la literatura castellana.

En el Renacimiento, y coincidiendo con la obrita de Lope de Rueda, tenemos noticia de otros dos textos en lengua española, que se basan por una parte en la tradición clásica y que por otra incorporan elementos del motivo de $\mathrm{Cu}$ caña de la literatura europea, omitiendo naturalmente todas las alusiones obscenas. El romance titulado La isla de Jauja ${ }^{19}$ pertenece al género de los romances nuevos y está conservado en un pliego suelto sin fecha. Es una especie de impreso de propaganda para invitar a los hidalgos a afiliarse a la conquista de América, y en él se enumeran largas listas alimentarias. Pero con diferencia al ya mencionado dit o la versión inglesa llamada The Land of Cockaygne predominan en este texto las descripciones en la tradición de la Jerusalén celeste. $\mathrm{La}$ isla está llena de metales y piedras preciosos, conforme con la visión que se tenía de las tierras de la Nueva India. La mención de 400 iglesias, ermitas y santuarios no se encuentra en ningún otro texto y refleja claramente la influyente posición de la Iglesia católica en la conquista de América.

Una obra italiana del mismo tema, el Capitolo, qual narra l'essere d'un mondo nuovo trovato nel Mar Oceano, recoge más los elementos subver-

17 Storia de Campriano contadino, a cura di Albino Zentti, Bologna, Preso Gaetano Romagnoli, 1884, págs. 55-61; el texto latino en J. Grimm/A. Schmeller, eds., Lateinische Gedichte des X. und XI. Jahrhunderts, Göttingen, Dieterichsche Buchhandlung, 1838, págs. 354-383.

$18 \mathrm{M}$. Chevalier, ed., Cuentos españoles de los siglos XVI y XVII, Madrid, Taurus, 1982.

10 "La isla de Jauja", en A. Durán, ed., Romancero general o colección de romances castellanos anteriores al siglo XVIII, vol. 2, BAE vol. 16, Madrid, Ediciones Atlas, 1945, págs. 393-395. Para otro texto similar véase Antonio Rodríguez Mofíno, Diccionario bibliográfico de pliegos sueltos poéticos (siglo XVI), Madrid, Castalia, 1970, número 862, y B. J. Gallardo, Ensayo de una biblioteca española de libros raros y curiosos, vol. 1, Madrid, Rivadeneyra, 1863, número 800. 
sivos al igual que sus antecedentes de la Edad Media, describiéndose al estilo de Rabelais escenas de grandes comilonas sin renunciar tampoco a groserías y obscenidades:

Il Re del luoco ha nome Bugalosso, / Perché è il piú poltron lo han fatto $\mathrm{Re} /$ Che come un gran pagliaio è grande e grosso. / Tanto è sattollo $\mathrm{e}$ grasso, che da sé / Mai mover non si vuol, perché gl'increscie, / Né vuol sentir de la fatica un che, [...] E del suo culo la manna li n'escie / E quando sputa, sputa marzapani, / [... ${ }^{20}$.

Otro testimonio español del mismo motivo se halla en los Diálogos de la montería, de Barahona de Sotos, escrito en el último tercio del siglo $\mathrm{xvI}^{21}$. Los países imaginarios aparecen aqui como fanfarronadas de caza y retoman la tradición de la literatura latina clásica como se conoce por ejemplo del poeta Caro Lucrecio.

Por todo lo dicho nos parece poco probable que Lope de Rueda haya utilizado como referente algunos modelos españoles a la hora de componer el quinto paso del Deleytoso. Así pues, la ausencia de una tradición española del motivo cucañero medieval es evidente.

Los grandes conocimientos de Lope de Rueda sobre la literatura italiana se manifiestan en sus comedias que tienen sus origenes en la commedia del cinquecento. También queda comprobado que Lope de Rueda hablaba o por lo menos leía el italiano con soltura ${ }^{22}$. Por estas razones y por la coincidencia de la combinación Tierra de Jauja-burla en varios textos italianos vemos en el paso quinto del Deleitoso, a diferencia de quienes intentan situar la obra de Lope de Rueda en un contexto exclusivamente español, una gran afinidad con Italia.

\footnotetext{
20 Piero Camporesi, La maschera di Bertoldo. G. C. Croce e la letteratura carnevalesca, Torino, Giulio Einaudi, 1976, págs. 305-312, aquí pág. 310.

21 Barahona de Sotos, Dí́logos de la montería, Madrid, La Sociedad de los Bibliófilos Espafioles, 1890, aquí págs. 356-359.

2s Lucia Lazzerini, "Quelques réflexions à propos du plurilinguisme théâtral au $\mathrm{xvI}^{\circ}$ siècle", en M. Lazard, ed., Aspects du théâtre populaire en Europe au XVI' siècle. Actes du colloque de la S. F. D. S., Paris, 1989, págs. 181-189.
} 